SUR Y TIEMPO. REVISTA DE HISTORIA DE AMÉRICA. №2, 2020.

\title{
La prensa política de mujeres en el Cono Sur 1900-1950
}

\author{
The Women's Political Press in Southern Cone 1900-1950
}

\section{Claudia Montero}

Universidad de Valparaíso, Chile Instituto de Historia y Ciencias Sociales

claudia.montero@uv.cl

\section{Resumen}

Este artículo presenta un análisis comparado de la prensa política de mujeres en los países del Cono Sur (Argentina, Uruguay y Chile) entre 1900 y 1950. El contexto son los cambios modernizadores que posibilitan nuevas subjetividades que se tradujeron en discursos feministas. Se define feminismo para el Cono Sur en la primera mitad del siglo XX, identificando cuatro tipos de prensa política de y para mujeres. El análisis se realiza considerando un marco teórico del espacio público y la teoría feminista. Se plantea que la prensa política de y para mujeres permitió la articulación de grupos con objetivos políticos particulares y expresó una diversidad de discursos feministas. Además, fue la manifestación de nuevas prácticas culturales que transgredían las concepciones tradicionales sobre lo femenino. La prensa entregó las mismas posibilidades para que las mujeres la asumieran como un medio de expresión, encuentro y consolidación de las nuevas figuras femeninas que representaban.

Palabras clave: Prensa de mujeres; Cono Sur; Espacio público; feminismo; siglo XX

\begin{abstract}
This paper presents a comparative analyzes about women's political press in Southern Cone's countries (Argentina, Uruguay y Chile) between 1900 y 1950. Modernization's transformations are the context that enable new subjectivities that were translated into feminist discourses. It is defined feminism for the beginning of the $20^{\text {th }}$ Century. Four types of women's political press are defined as well. The analysis is carried out considering a theoretical framework of public sphere and feminist theory. It is argued that the women's political press allowed the articulation of groups with particular political objectives and expressed a diversity of feminist
\end{abstract}


discourses. It was also the manifestation of new cultural practices that transgress traditional conceptions of the feminine. The press gave the same possibilities for women to assume it as a means of expression, encounter and consolidation of the new female figures they represented.

Keywords: Women's Press; Southern Cone; Public Space; Feminism; 20th Century

\section{Introducción}

El objetivo de este trabajo es analizar comparativamente la prensa política de y para mujeres de los países del Cono Sur (Argentina, Uruguay y Chile) considerando demandas feministas. El período 1900 y 1950 coincide con el proceso de modernización de la región y es el marco de la emergencia de nuevas subjetividades femeninas. Estas subjetividades se tradujeron en discursos feministas que se plasmaron en la prensa política de y para mujeres, transformando las prácticas culturales asociadas a lo femenino. Ésta prensa se define como aquella que analiza la condición de las mujeres en la sociedad, y expresa la demanda de derechos políticos, sociales y/o culturales, y que difunde el ideario de grupos de mujeres ${ }^{1}$.

Considerando que los países del Cono Sur poseen una matriz cultural similar, el proceso de modernización fue diferente por la envergadura de los desarrollos económicos y las características de los sistemas políticos de cada país². Mi argumento es que, pese a estas diferencias, la experiencia de exclusión femenina fue similar en Argentina, Uruguay y Chile. La prensa política de y para mujeres permitió la articulación de grupos con objetivos políticos particulares y expresó una diversidad de discursos feministas. Además, fue la manifestación de nuevas prácticas culturales que transgredían las concepciones tradicionales sobre lo femenino. Como objeto cultural, en uno y otro país, entregó las mismas posibilidades para que las mujeres la asumieran como un medio de expresión, encuentro y consolidación de las nuevas figuras femeninas que representaban.

\footnotetext{
1 Existe una producción de prensa femenina en los tres países que sobrepasa la calificación de prensa política asociada a la reivindicación de derechos. Entre ella encontramos la prensa de mujeres católicas, con amplio desarrollo en Chile, Uruguay y en menor medida en Argentina. Además, existe una prensa desarrollada por mujeres de tipo cultural y otra de tipo comercial.

2 El proceso de modernización se vivió en los países del Cono Sur de forma similar ya que entraron en la economía mundial como exportadores de materias primas. Ello repercutió en el aumento de ingresos que activó la actividad industrial, aumentó la urbanización, las inversiones en servicios públicos, la burocracia estatal y la migración. Este desarrollo generó desigualdades sociales y mantuvo una estructura excluyente. La diferencia entre los países se dio por el volumen y alcance de las transformaciones. Por ejemplo: la inmigración europea en Argentina fue de 72,5\% en 1914 y de $47,1 \%$ en Uruguay en 1908. El crecimiento de la población fue: 1.575 .814 habitantes en Buenos Aires en 1895 y 2.981 .043 en 1914. Montevideo 309.000 en 1890 y 708.233. Santiago 256.403 en 1895 y 553.458 en 1920.
} 
En la primera parte de este trabajo se presenta una definición de feminismo para el Cono Sur en la primera mitad del siglo XX. En segundo lugar se realiza una caracterización de la prensa política de y para mujeres. El análisis se realiza considerando tipos de prensa política de y para mujeres: de obreras y feminista. Existen dos tipos más para el mismo período: la prensa de mujeres asociadas a partidos políticos tradicionales y la asociada a la defensa de causas internacionales; sin embargo su análisis sobrepasa las posibilidades de este trabajo3 ${ }^{3}$.

Hasta ahora no existen trabajos comparativos sobre prensa de mujeres en el Cono Sur. Ésta se ha estudiado en Argentina y Chile, caracterizándola como una estrategia particular de las mujeres para expresar subjetividades y proyectos

${ }^{3}$ Las existencias para esos tipos son las siguientes:

Tabla: Prensa de mujeres de partidos políticos en el Cono Sur (1900-1950)

\begin{tabular}{|c|c|c|}
\hline Argentina & Uruguay & Chile \\
\hline $\begin{array}{l}\text { Mujeres Argentinas. Vocero } \\
\text { Comunista (Buenos Aires 1946- } \\
\text { 1948) Partido Comunista } \\
\text { argentino. Directora: Alcira de } \\
\text { la Peña. }\end{array}$ & $\begin{array}{l}\text { Mujer Batllista/ Comité de } \\
\text { Organización femenina Batllista } \\
\text { Doña Matilde Pacheco de Batlle } \\
\text { y Ordóñez (Montevideo 1946) } \\
\text { Directora: Alba Roballo de } \\
\text { Previtali }\end{array}$ & $\begin{array}{l}\text { Política Feminista (Valparaíso } \\
\text { 1931-1932) Juventud Liberal } \\
\text { Democrática. }\end{array}$ \\
\hline $\begin{array}{lrr}\text { Humanidad } & \text { nueva. Revista } \\
\text { Socialista } & \text { Internacional } \\
\text { (Buenos Aires } 1908-1919) \\
\text { Directora: Alicia Moreau. }\end{array}$ & & $\begin{array}{lr}\text { Lealtad (Santiago } & \text { 1934-1938) } \\
\text { Partido } & \text { Femenino } \\
\text { Alessandristar } & \end{array}$ \\
\hline & & $\begin{array}{l}\text { Camarada (Santiago 1939) } \\
\text { Mujeres socialistas. }\end{array}$ \\
\hline & & $\begin{array}{l}\text { Trinchera (Valdivia 1939- } \\
\text { 1940) Juventud Socialista, de la } \\
\text { Acción de Mujeres Socialistas. }\end{array}$ \\
\hline & & $\begin{array}{l}\text { La mujer en marcha (Santiago } \\
\text { 1953) Órgano oficial del } \\
\text { Partido Nacional Femenino } \\
\text { Ibañista. }\end{array}$ \\
\hline
\end{tabular}

Tabla: Prensa de mujeres de organizaciones varias/internacionales en el Cono Sur (19001950)

\begin{tabular}{|c|c|c|}
\hline Argentina & Uruguay & Chile \\
\hline $\begin{array}{lrr}\text { Frente Único. Frente } & \text { único } \\
\text { Popular Argentino y Federación } \\
\text { Antiguerra de } & \text { Mujeres } \\
\text { Argentinas. (Buenos } & \text { Aires } \\
\text { 1935). } & & \\
\end{array}$ & $\begin{array}{l}\text { Acción Americanista: boletín de } \\
\text { la "Liga femenina de } \\
\text { Confraternidad Americana", } \\
\text { (Montevideo 1943) Directora: } \\
\text { María Luisa Herrera de } \\
\text { Gutiérrez. }\end{array}$ & \\
\hline $\begin{array}{l}\text { Centro Femenino de Asistencia } \\
\text { a los Prisioneros Italianos de } \\
\text { Guerra (Buenos Aires 1944). }\end{array}$ & $\begin{array}{l}\text { Acción Femenina por la } \\
\text { Victoria. Periódico de ayuda a } \\
\text { las naciones liberadas de los } \\
\text { fascismos, (Montevideo 1946). }\end{array}$ & \\
\hline
\end{tabular}


políticos, asociados a una estética propia4. En este trabajo se sistematizan las investigaciones sobre el tema y se avanza con un planteamiento original que recoge nuevos antecedentes gracias al trabajo de archivo realizado en los tres países. Se muestra un panorama amplio, incluyendo producciones que previamente no habían sido consideradas en los análisis. Aún más importante, permite visibilizar comparativamente la importancia de la prensa como objeto cultural para un grupo social excluido como las mujeres.

El marco temporal de este trabajo es la primera mitad del siglo XX. América Latina vive las transformaciones del proceso de modernización (iniciado a fines del siglo XIX) que se vincula al desarrollo y triunfo mundial del capitalismo (Hobsbawm, 1998), y se entronca con la experiencia de la modernidad. Esta implica un cambio en la experiencia vital de los sujetos sociales (Berman, 1994), que se asumen tanto transformadores del mundo como transformados por él. En el caso de las mujeres del Cono Sur, el sentir moderno se expresó en la emergencia de nuevas subjetividades que cuestionaron el lugar asignado por el patriarcado e irrumpieron con nuevas prácticas culturales, como el ser escritoras, editoras y feministas.

En el análisis de la prensa política de y para mujeres, el concepto de espacio público es un elemento teórico importante, ya que es en ese lugar donde circulan las publicaciones. Las ideas de Nancy Fraser (1992) son útiles para pensar la prensa de América Latina, como lo ha demostrado Mirta Lobato (2009) en su trabajo sobre prensa obrera del Río de La Plata. Fraser define un espacio público considerando las características de sociedades estratificadas como las latinoamericanas. Éstas se caracterizan, según los planteamientos de Halperín Donghi (1985), por poseer estructuras institucionales con grupos sociales desiguales y que propician relaciones de dominación y subordinación. Esto se extiende a las relaciones de género sexual (lo que se puede reconocer en la prensa de mujeres). Fraser plantea un espacio público como un lugar de interacción discursiva, con una dimensión compleja, ya que sería un ideal utópico no realizado, ideológicamente masculinista y legitimador del dominio de la clase privilegiada. Frente a la desvalorización de los aportes de los grupos subordinados como las mujeres, Fraser rescata su acción como contrapúblicos subalternos. Estos generan contra-discursos que les permite formular otras interpretaciones sobre ellos mismos, sus intereses e identidades.

A partir de estas consideraciones se puede comprender por qué el patrón de Carmela Jeria le da un ultimátum para despedirla. Una mujer que decide generar opinión a principios del siglo XX en América Latina y el Cono Sur habla de la persistencia de los controles sobre los grupos de subordinados a los que se refiere Fraser. Además, la dificultad de llevar a cabo una publicación política de y para

\footnotetext{
4 Este análisis está menos desarrollado en Uruguay, donde sólo se ha relevado la producción de prensa femenina asociada a la historia de las organizaciones de mujeres.
} 
mujeres habla de un orden social jerarquizado por normas de género. En este sentido, los planteamientos de Joan Scott (1996) son fundamentales para comprender el orden social en el que se desarrollaron estas publicaciones. Para una historia de la prensa de mujeres a inicios del siglo XX ayuda a comprender cómo las condiciones sociales, políticas, económicas y culturales juegan un papel más complejo que las concepciones binarias en torno a lo femenino y masculino. La existencia de la prensa de mujeres en el Cono Sur no niega la exclusión de las mujeres de la política formal, sino que da cuenta de ella. Además expresa cómo las mujeres jugaron con los roles de género establecidos para mostrar precisamente el encasillamiento en el que vivían.

La prensa es entendida como objeto cultural, es decir, como una expresión de las condiciones en las que se produjo (Chartier, 1992). Esto permite relacionar la variedad de tipos de publicaciones que definimos (de obreras, feministas) con, por ejemplo, la agitación que causó la modernización en la sociedad y cómo estos cambios afectaron la cotidianeidad de los sujetos, su forma de entenderse a sí mismos y sus proyectos de identidad. En este caso, las mujeres usaron la prensa como medio de expresión, apropiándose de las posibilidades que entregaba el medio como objeto material. De tal forma, este trabajo rescata las publicaciones como objeto de análisis en sí mismas, como poseedoras de una multiespacialidad en una entrega única, en un momento y lugar determinado, adquiriendo significación que se despliega en sus discursos textuales, gráficos y de diagramación (Osuna, 1998).

\section{Feminismo en el Cono Sur}

El feminismo es un fenómeno propio de la modernidad y se refiere a un discurso que cuestiona la condición subordinada de las mujeres dentro del sistema patriarcal, reivindicando mejoras en la situación vital. Esta subordinación está dada por relaciones de sexo-género que evidencian una dominación sobre las mujeres ejercida por instituciones sociales de predominio masculino (De Miguel, 1995). Sin embargo, el feminismo debe considerarse como un fenómeno diverso, ya que posee manifestaciones distintas de acuerdo con momentos históricos, posiciones ideológicas, entre otros factores (Nash, 2004). En América Latina, las primeras manifestaciones feministas coinciden con el proceso de modernización, y desde un principio fue un fenómeno plural, aunque sólo referido a la clase. Las especificidades de las mujeres negras, indígenas y campesinas no formaban parte del discurso feminista del Cono Sur de inicios del siglo XX. Los primeros feminismos del Cono Sur fueron de mujeres de la ciudad, en un momento en el que ser blanco/a daba la legitimidad como habitante urbano/a. El silencio de las dobles o triples exclusiones de mujeres negras, indígenas o campesinas habla del ideal europeizante de las 
naciones latinoamericanas de principios del siglo XX, del que las mujeres no estaban exentas.

En Argentina, Uruguay y Chile, las mujeres se organizaron políticamente desarrollando contradiscursos sobre la base de la exclusión de sexo y género, y del cuestionamiento a las tensiones provocadas por el desarrollo económico y los cambios sociales. Así, las mujeres de elite desarrollaron el feminismo liberal y las obreras los feminismos socialistas o anarquistas ${ }^{5}$. Demandaron derechos para ser consideradas no sólo "objetos de modernización" a través de políticas públicas, sino como "sujetos de modernización" (Berman, 1994). Esto último implicaba hacer extensiva cierta autonomía que habían conseguido al ingresar al mundo laboral. Estas inquietudes, sumadas a la influencia de las inmigrantes europeas (éstas últimas con un impacto mayor en los países del Río de la Plata), impulsaron la consolidación del movimiento de mujeres y de los discursos feministas en los tres países (Molyneux, 2003).

\section{Prensa de mujeres en el Cono Sur}

Desde el siglo XIX existieron mujeres haciendo prensa en la región. En Argentina, la primera publicación fue de 1830, en Chile de 1865 y en Uruguay de 1894. En general, las publicaciones de este período fueron realizadas por mujeres de elite con el objetivo de legitimar la voz femenina en el espacio público. Sin buscar transgredir límites, aunque eran conscientes de que lo hacían (Masiello, 1994), usaron formatos y temas acomodándolos a lo que se esperaba de una mujer de bien. Se preocupaban por los problemas del país y no buscaban hacer una crítica patriarcal (Belluci, 1994; Montero, 2013).

En el siglo XX se inicia un nuevo período en la historia de la prensa de mujeres. Las herederas de las pioneras de la prensa del siglo XIX asumen el deber de resguardar el lugar abierto en el espacio público. A partir de 1900 hay una explosión de publicaciones hechas por mujeres en los tres países. No sólo hacen prensa política, sino que hacen prensa cultural y comercial. Esta diversidad muestra el cambio cultural que implicó el cuestionamiento a los roles tradicionales de las mujeres y que significó nuevas formas de relaciones y de cómo se entendían las mujeres a sí mismas: escribían, publicaban y leían en nuevos espacios urbanos.

Los cambios modernizadores otorgaron condiciones de posibilidad para que nuevos grupos como las mujeres accedieran a producir publicaciones. Las nuevas tecnologías bajaron los costos de publicación y el aumento en la alfabetización permitió que tuviera sentido la edición de periódicos y revistas para difundir nuevas

\footnotetext{
5 Es importante consignar que el activismo femenino de inicios del siglo XX también incluyó a mujeres conservadoras que se organizaron para mantener el orden tradicional.
} 
ideas ${ }^{6}$. En Chile, esto se combinó con un espíritu liberal que permitió la expresión de los nuevos sujetos sociales (Subercaseaux, 1989: 97). En Argentina y Uruguay, la llegada de inmigrantes fue fundamental para la consolidación de una cultura letrada que privilegiaba la publicación de medios como forma de expresión (Lobato, 2009: $34)$.

La prensa política de y para mujeres se desarrolló en un contexto de auge de prensa comercial que establecía patrones de género para las publicaciones. Luchó contra los prejuicios que dividían secciones serias para varones y de entretención para mujeres (Poblete, 2003). Su objetivo era posicionar a las mujeres como productoras y lectoras de análisis sobre el sistema político y sus límites, generando un cambio cultural profundo en la consideración de lo que debía ser una mujer. Con estas claves se deben entender su forma de circulación y sus formatos, secciones y diagramación. Esta prensa no respondió a una demanda de mercado. Formó parte de un circuito no comercial de publicaciones producidas por grupos políticos. Cumplió la función de visibilizar al colectivo femenino como un contrapúblico. Esto significa que las mujeres, en tanto se asumían sujetos sociales, eran capaces de formar un público que desafiaba al público burgués (Fraser, 1992). Estas publicaciones generaron discusión y controversia, difundieron un ideario particular (Lobato, 2009: 16), y a la vez fueron un lugar de sociabilidad y formación de las propias militantes al interior de la organización. Estas funciones se tradujeron en los formatos de las publicaciones. En ellas había secciones dedicadas a la difusión de las actividades de la organización, documentos internos como actas de reuniones, declaraciones de principios, etc. Sin embargo, lo que caracteriza a esta prensa fue la presencia de textos que califican como ensayo de género (Pratt, 1995). En todas las publicaciones, ya sea revistas o periódicos, de feministas liberales, socialistas o anarquistas, encontramos este tipo de textos que contesta y desafía las narrativas masculinistas sobre la cultura y la historia (Pratt, 1995).

\section{La Prensa de y para Mujeres Obreras en el Cono Sur}

La prensa de obreras en los países del Cono Sur es heterogénea. Responde a la influencia de ideologías como el anarquismo y el socialismo, y desde el fin del siglo XIX, visibilizó exclusiones de clase, sin considerar las de raza o etnia. En Argentina, en 1896 se publicó La Voz de la Mujer, que se definía como "periódico comunista anárquico". Afortunadamente, este medio sobrevivió a los prejuicios de género de las políticas de conservación y se puede acceder en la actualidad, e incluso

\footnotetext{
${ }_{6}^{6}$ En Argentina, el analfabetismo descendió del 77,9\% en 1869 al 35\% en 1914. En Uruguay del 40,6\% en 1900 al 29,5 en 1920, y en Chile del 68,2\% en 1895 al 50\% en 1920.
} 
fue reeditada por la Universidad de Quilmes7. Lamentablemente no corrió la misma suerte el periódico chileno La mujer (1897) de obreras de Valparaíso en Chile, del que sólo tenemos referencia de su existencia a través de una nota que se publicó en un periódico de mujeres de elite de la misma fecha (Montero, 2015). Los estudios sobre estos medios han sido calificados de diversa forma: por ejemplo, Belluci (1994) los denomina "prensa contestataria" o "prensa feminista-anarquista" (Fuentes, 2008). Sin embargo, existe un acuerdo en que son una expresión de feminismo. En general se concentran en el inicio del siglo. Esto se debe al momento particular del movimiento obrero en el Cono Sur, fortalecido por las contradicciones generadas por el proceso de modernización. Junto a ello, se debe considerar el efecto que tuvo para las organizaciones de mujeres de estos países la visita de Belén de Sárraga. Ella fue una librepensadora española que visitó América Latina y que influyó en la formación de las primeras organizaciones de mujeres en Chile y en la fundación de periódicos en el Río de la Plata.

Tabla 1: Prensa de y para Mujeres Obreras en el Cono Sur (1900-1950)

\begin{tabular}{|c|c|c|}
\hline Argentina & Uruguay & Chile \\
\hline $\begin{array}{l}\text { Nosotras (La Plata 1902- } \\
\text { 1904) María Abella }\end{array}$ & $\begin{array}{l}\text { El Liberal } \text { (Montevideo } \\
\text { 1908-1910) Belén de } \\
\text { Sárraga }\end{array}$ & $\begin{array}{l}\text { La Alborada (Valparaíso } \\
\text { 1905-1907) Carmela Jeria }\end{array}$ \\
\hline $\begin{array}{l}\text { La voz del pueblo (Salta } \\
\text { 1905) Sarah Bergara }\end{array}$ & 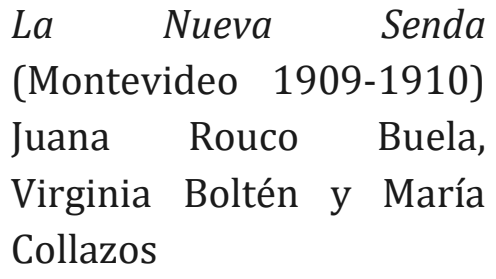 & $\begin{array}{l}\text { La Palanca (Santiago } \\
\text { 1908) Ester Díaz }\end{array}$ \\
\hline $\begin{array}{l}\text { Tribuna Femenina (s/d } \\
1915-1916)\end{array}$ & $\begin{array}{l}\text { La Batalla (Montevideo } \\
\text { 1915-1927) María Collazo }\end{array}$ & $\begin{array}{l}\text { El Despertar de la Mujer } \\
\text { Obrera (Santiago 1914) }\end{array}$ \\
\hline $\begin{array}{ll}\text { Nuestra } & \text { Tribuna } \\
\text { (Necochea 1922 y 1924) } \\
\text { Juana Rouco Buela y } \\
\text { Virginia Boltén }\end{array}$ & $\begin{array}{l}\text { Boletín informativo del } \\
\text { Sindicato U. de la aguja } \\
\text { (Montevideo 1931-33) }\end{array}$ & \\
\hline
\end{tabular}

La prensa de mujeres obreras relacionada con el anarquismo se dio en los países del Río de la Plata. De hecho, las activistas anarquistas más reconocidas, Juana Rouco Buela, María Abella y Virginia Boltén, vivieron entre ambos países y son reclamadas por las genealogías feministas tanto del Uruguay como de Argentina. Sin embargo, considerando los principios del anarquismo y del feminismo, hace sentido

7 Esta edición facsimilar fue publicada en 1997 en la colección La Ideología Argentina, bajo la dirección de Oscar Terán. 
pensar la acción de estas mujeres de forma transnacional, superando el encasillamiento en historias nacionales. Activistas europeas que arribaron a uno y otro lado del Río de la Plata, comprometidas en el movimiento de trabajadores, dieron vida a esta prensa. Establecieron las bases para un feminismo anarquista rioplatense relacionado con el movimiento europeo, más que con otros países latinoamericanos. Aunque existió relación con Chile y Brasil, faltan estudios que profundicen el análisis y alcance de estas relaciones; y aún no ha surgido como problema una posible articulación de éstos con otras regiones de América Latina.

Una de las características del periodismo ejercido por estas mujeres es que no era profesionalizado. Era una actividad voluntaria, discontinua y su gran objetivo era la formación política (Belluci, 1994: 256-257). Se la reconoce como una expresión de mujeres conscientes del sometimiento que vivía el género femenino en tanto trabajadoras y madres. Esto implicaba una crítica al sistema capitalista que condenaba a las obreras en razón de su género (Feijóo, 1994). Sin embargo, esta crítica se hacía desde una matriz anarquista, subordinándose a este discurso que las consideraba sólo como compañeras dentro de movimiento. El rol de las mujeres anarquistas era estimular la militancia de hijos, maridos y hermanos (Barrancos, 1989: 276), generando tensiones en el discurso feminista de las anarquistas.

A pesar de las tensiones, las anarquistas estuvieron en la vanguardia de una acción transgresora que visibilizaba la situación de las mujeres como un problema fruto de una sociedad con desarrollo desigual. En ese sentido, representaron un cambio en la cultura al instalar nuevas figuras femeninas en el espacio público latinoamericano, producto de una nueva subjetividad de mujeres que cuestionaban las normas burguesas de comportamiento femenino. Así, un periódico con el título como "Ni Dios, Ni Patrón, Ni Marido", representó lo abyecto de un fenómeno que ni siquiera los propios anarquistas querían mirar. De la misma forma, se debe entender el rechazo hacia las feministas liberales, ya que coherentes con su ideología, las anarquistas rehusaron apoyar causas relacionadas con el orden burgués. Así se entiende el gran silencio en la prensa feminista anarquista sobre el sufragismo. Esto ha sido calificado por Barrancos (1989) como un "contrafeminismo del feminismo anarquista".

Los temas fundamentales para el anarquismo feminista se relacionaban con los distintos ámbitos en que las mujeres se veían desmedradas. En el trabajo proponían igualdad de condiciones para mejorar la situación de las trabajadoras, considerando el trinomio mujer-trabajo-maternidad. Por otra parte, cuestionaron la institución de la familia burguesa, proponiendo el amor libre para que las mujeres recuperaran su autonomía como sujetos y tomaran sus propias decisiones. Esto se relacionó además con campañas de profilaxis, cuyo objetivo era defender a las mujeres del contagio de enfermedades venéreas, el derecho a anticoncepción y al 
aborto. Lucharon por una educación femenina alejada de normas de género que formaban a las niñas en la domesticidad influida por la iglesia, y demandaron el acceso a una educación científica que les permitiera alcanzar todo su potencial. Un resumen de estos planteamientos se puede ver en la siguiente intervención de Juana Rouco Buela en el número 1 del periódico La Nueva Senda (Montevideo, 1909-1910), que dirigió junto con Virginia Boltén y María Collazos, todas anarquistas y feministas reconocidas en ambos lados del Río de la Plata:

Oh la ley! La une para siempre (según ellos) con un hombre también como ella víctima de la sociedad actual, cuando no resulta un degenerado que en este caso será doblemente víctima, obligada por la ley a obedecerle ciegamente puesto que él se considera patrón y dueño del hogar formado.

De modo que en esta maldita sociedad la mujer tiene que estar continuamente subyugada: primero bajo la férula maternal que la castiga para que la sociedad no critique sus actos, mientras que por otro lado la corrompe; luego bajo el látigo oprobioso del patrón infame y tirano y por último bajo el despotismo de un degenerado cualquiera que con ínfulas de autorizado por la ley y la sociedad, hace de ella una verdadera mártirs.

$\mathrm{Al}$ estar conscientes de que las obreras vivían más de una explotación (la del trabajo y el hogar), las anarquistas feministas propusieron y alentaron la organización de las mujeres para visibilizar las luchas específicas. Así se celebraba la propuesta de organización de Virginia Boltén:

al cual deberían formar parte todas las mujeres que hayan comprendido la necesidad de implantar una nueva sociedad, en la cual los seres puedan vivir libremente y las mujeres podremos ser madres amorosas y leales compañeras del hombre y no víctimas y esclavas como actualmente. (...) La libertad que anhelamos depende solo de nosotras mismas. 9

En Chile, la prensa política de obreras formó parte del movimiento socialista. Sin embargo, en la medida que las mujeres se hicieron más conscientes de la especificidad de su condición, fueron asumiéndose feministas (Hutchison, 2006: 122). Las directoras de los periódicos emblemáticos La Alborada y La Palanca se asumieron voceras de la defensa de las condiciones laborales de las obreras y denunciaron las relaciones violentas en la intimidad del hogar. Para Elizabeth

${ }^{8}$ La Nueva Senda, Montevideo, 18 de setiembre de 1909.

${ }_{9}$ La Nueva Senda, nํ⒊ 
Hutchison (2006) hubo una articulación entre problemas femeninos y el discurso de la lucha de clases, mientras que María Angélica Illanes (2012: 15) plantea una conciencia de género en la demanda de las obreras. Esta idea que se puede observar en opiniones como la siguiente: "¡Vaya! Por fin el sexo femenino se ha armado del elemento que más efecto hace ante la opinión pública: el periódico. Ahora no les andarán con 8 y 9 a las pobres obreras que vegetan por esos talleres" 10 .

Las obreras chilenas dan cuenta de la falta de interés de los dirigentes obreros por la emancipación femenina. Por lo tanto, asumen una postura crítica adjudicándose una posición propia, de avanzada y autónoma. Sin duda representan una figura femenina nueva. A partir de este momento se puede hablar de feministas obreras:

cuando las hijas del pueblo se encuentren libre, por completo, de añejas precauciones, de torpes rutinas, entonces caminaran resueltas y serenas, protejidas (sic) por sus propias enerjias (sic) intelectuales, a conquistar aquellos derechos que hasta hoy (sic) han sido monopolio esclusivo (sic) del hombre.11

Al igual que sus compañeras del Río de la Plata, las reivindicaciones de las chilenas eran sobre las mejoras en las condiciones laborales, considerando el trinomio mujer-trabajo-maternidad. No existe pronunciamiento sobre las exclusiones de raza o etnia. Demandaban una educación que procurara libertad de pensamiento a las mujeres y las alejara de prejuicios. Repudiaron la violencia física contra las mujeres ejercida por los propios compañeros de clase, como se denunció en la siguiente cita:

Maltratar a la madre de nuestros hijos ¿no es abofetear el rostro de nuestros descendientes, insultar las generaciones futuras? [...] Estos tratamientos vergonzosos se están generalizando demasiado entre nosotros para que sigamos haciéndolos cómplices con el silencio.12

En la prensa política de las obreras chilenas siempre hubo tensión entre la identidad de mujeres proletarias y la identidad de obreras. Las primeras no desafiaron los roles de madre y esposa, pero sí demandaron cambios respecto a la intimidad de la vida matrimonial. Por su parte, como obreras denunciaron las condiciones laborales de las mujeres y se proclamaron compañeras del obrero en la lucha contra el capitalismo. El feminismo obrero en Chile, como el feminismo

\footnotetext{
10 SAKT, "Charlas", La Alborada, no 1 (10 de septiembre de 1905), p. 4.

11 Jeria, Carmela, "Tras el bienestar", La Alborada, no 17 (Segunda quincena de Julio de 1906), p. 1.

12 Guerrero 0, Ricardo, “¡Cómo tratamos a la mujer!”, La Alborada, no 20 (18 de noviembre de 1906), p. 2.
} 
anarquista de las rioplatenses, mantuvo nociones ambivalentes y contradictorias. Sin embargo, se alzaron como figuras femeninas nuevas dentro de una cultura patriarcal, propiciando un cambio en las formas de relaciones. Este fenómeno se materializó en un objeto cultural que circuló en las sociedades del Cono Sur, difundiendo la emergencia de mujeres que representaron subjetividades nuevas en un contexto de modernización.

\section{La Prensa Feminista en el Cono Sur}

Este es un grupo de publicaciones heterogéneo tanto dentro de cada país como en la comparación internacional. Se definen como revistas y periódicos producidos por mujeres que plantean el "problema femenino" o la "cuestión de la mujer". Visibilizan la exclusión femenina de sexo-género, sin considerar las dobles o triples exclusiones de raza o etnia. El feminismo de principios del siglo XX en los países del Cono Sur, al tener que legitimarse dentro de una sociedad que quería ser blanca y civilizada, no consideró a indígenas, negras o campesinas.

Como ya mencionamos en el apartado sobre la prensa de las obreras, hacia 1900 en los países del Cono Sur, producto de las transformaciones sociales y culturales que vivían las mujeres en el contexto de modernización, emerge la denuncia por exclusiones a las que estaban sometidas. Las mujeres habían iniciado un activismo que las ponía en una situación de sujetos sociales, conscientes de sus capacidades en la vida social de los países. Así, demandaron igualdad jurídica, social y política, desde organizaciones autodefinidas como feministas, aunque con diferencias en la radicalidad de las críticas. Por ejemplo, la acción feminista en Argentina tuvo un fuerte impulso desde el socialismo, con militantes que defendieron los derechos de las mujeres, como Alicia Moreau (Barrancos, 2007). También hubo otras expresiones como la alianza de feministas de diverso cuño en la revista La nueva mujer (La Plata, 1910-1912). Esta fue dirigida por Julieta Lanteri, una feminista que podríamos calificar de autónoma, junto con María Abella Ramírez, conocida anarquista.

En Chile y Uruguay, el feminismo se caracterizó por ser una expresión de mujeres autónomas de partidos políticos. Si bien en su discurso recogieron elementos del socialismo, tanto las feministas uruguayas como las chilenas formaron sus propios partidos políticos u organizaciones para la defensa de sus derechos. Una diferencia sustancial, se relaciona con la potencia del discurso. El feminismo chileno, sobre todo el desarrollado hasta la década de 1920, posee un tono de cautela. Existía temor a la descalificación y demonización de las feministas, quienes realizan sus reclamos amparadas en discusiones de principios filosóficos y apoyadas en la ley (Kirkwood 1990). Por su parte, las feministas argentinas y uruguayas estaban reñidas de radicalidad gracias a la fuerza con la que hacían sus demandas. 
La prensa política feminista es muy extensa, y para entenderla se puede dividir en tres momentos: 1900-1920, en el que se muestra un gran activismo feminista; 1930-1940, en el que existe una radicalización del feminismo dado el contexto de crisis que tuvo expresiones particulares en cada nación; y 1940-1950, en el que se ve una disminución de las publicaciones feministas como se habían entendido hasta ese momento.

Tabla 2: Prensa Feminista en el Cono Sur (1900-1950)

\begin{tabular}{|c|c|c|}
\hline Argentina 1900-1920 & Uruguay 1900-1920 & Chile 1900-1920 \\
\hline $\begin{array}{l}\text { Unión y Labor (Buenos } \\
\text { Aires 1909-1913) Petrona } \\
\text { Eyle, Matilde T. Flaitoro, } \\
\text { Sara Justo. }\end{array}$ & $\begin{array}{l}\text { La defensa de la Mujer } \\
\text { (Montevideo } \\
\text { Celestina Margain de } \\
\text { León. }\end{array}$ & $\begin{array}{ll}\text { La Aurora Feminista } \\
\text { (Santiago 1904) } & \text { Eulojia } \\
\text { Aravena de Rojas. }\end{array}$ \\
\hline 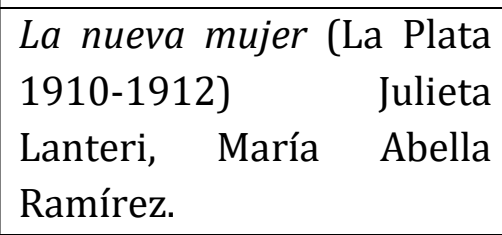 & $\begin{array}{lr}\text { Acción } & \text { Femenina } \\
\text { (Montevideo } & 1915-1924) \\
\text { Paulina Luisi. } & \end{array}$ & \begin{tabular}{lrr}
$a$ & Voz & \multicolumn{2}{r}{ Femenina } \\
(Santiago 1916) & Elisa \\
Valderrama. &
\end{tabular} \\
\hline \multirow[t]{4}{*}{$\begin{array}{l}\text { Nuestra Causa, Revista } \\
\text { Mensual del Movimiento } \\
\text { Feminista (Buenos Aires } \\
\text { 1919-1921). Petrona Eyle. }\end{array}$} & $\begin{array}{lr}\text { Revista } & \text { Feminista } \\
\text { Uruguaya, (Montevideo } \\
\text { 1921) Elisabeth Delpech } \\
\text { de Bertrán. }\end{array}$ & $\begin{array}{l}\text { Vida Femenina } \\
\text { 1919) Inés } \\
\text { Aldunate. }\end{array}$ \\
\hline & & $\begin{array}{lr}\text { Acción } & \text { Femenina } \\
\text { (Santiago } & 1922-1923 \text { y } \\
\text { 1934-1939) } & \text { Partido } \\
\text { Cívico Femenino. }\end{array}$ \\
\hline & & $\begin{array}{l}\text { Revista } \quad \text { Femenina } \\
\text { (Santiago 1924) Partido } \\
\text { Cívico Femenino. }\end{array}$ \\
\hline & & $\begin{array}{l}\text { Unión } \quad \text { Femenina } \\
\text { (Valparaíso 1927) Unión } \\
\text { Femenina de Chile. }\end{array}$ \\
\hline 1930-1940 & $1930-1940$ & $1930-1940$ \\
\hline $\begin{array}{llr}\text { ¡Mujer! } & \text { (Buenos } & \text { Aires } \\
\text { 1931) Revista de los } \\
\text { grupos femeninos del } \\
\text { Partido Socialista. }\end{array}$ & $\begin{array}{l}\text { Nueva América } \\
\text { (Montevideo 1932) Zulma } \\
\text { Núñez. }\end{array}$ & $\begin{array}{l}\text { Nosotras (Valparaíso } \\
\text { 1931-1935) Unión } \\
\text { Femenina de Chile. }\end{array}$ \\
\hline $\begin{array}{l}\text { Vida Femenina (Buenos } \\
\text { Aires, 1933-1941) Celina } \\
\text { L. Lacraux. }\end{array}$ & $\begin{array}{lr}\text { Asociación } & \begin{array}{r}\text { Estudiantil } \\
\text { Femenina }\end{array} \\
\text { 1933) Lilia E. Pazos, Clelia }\end{array}$ & $\begin{array}{l}\text { La Mujer Nueva (Santiago } \\
\text { 1935-1942) MEMCH. }\end{array}$ \\
\hline
\end{tabular}




\begin{tabular}{|c|c|c|}
\hline & Dotta Viglietti. & \\
\hline $\begin{array}{llr}\text { Mujeres } & \text { de } & \text { América } \\
\text { (Buenos } & \text { Aires } & 1944)\end{array}$ & $\begin{array}{lrr}\text { Ideas } y & \text { Acción } \\
\text { (Montevideo } & \text { 1933) }\end{array}$ & $\begin{array}{lrl}\text { Voz Femenina (Santiago } \\
\text { 1932) Partido Femenino }\end{array}$ \\
\hline Nelly Merino Carvallo. & $\begin{array}{l}\text { Partido Independiente } \\
\text { Demócrata Feminista. } \\
\text { Sara Rey Álvarez. }\end{array}$ & Nacional. Elvira Rogat. \\
\hline & $\begin{array}{l}\text { La Mujer (Montevideo } \\
\text { 1938) J. M. Pérez, I. Cl }\end{array}$ & $\begin{array}{l}\text { Unión Femenina de Chile } \\
\text { (Valparaíso 1934-1935) }\end{array}$ \\
\hline 1940-1950 & $1940-1950$ & $1940-1950$ \\
\hline $\begin{array}{l}\text { Nuestras Mujeres (Buenos } \\
\text { Aires 1948-1963) } 1955 \\
\text { UMA Directora: Matilde } \\
\text { Alemán }\end{array}$ & $\begin{array}{l}\text { Boletín de información de } \\
\text { "Unión femenina del } \\
\text { Uruguay adherida a la } \\
\text { federación demócrata } \\
\text { internacional de mujeres" } \\
\text { (Montevideo 1949) María } \\
\text { Julia Campistrous }\end{array}$ & $\begin{array}{l}\text { Boletín FECHIF (Santiago } \\
\text { 1944-1947) Federación } \\
\text { Chilena de Instituciones } \\
\text { Femeninas. }\end{array}$ \\
\hline $\begin{array}{l}\text { Ciudadanas } \begin{array}{c}\text { Unión de } \\
\text { mujeres }\end{array} \text { socialistas } \\
\text { (Buenos Aires 1956) } \\
\text { Comité de redacción: } \\
\text { Alicia Moreau, Matilde T. } \\
\text { de Muñoz, María L. } \\
\text { Berrondo, Antonia Díaz y } \\
\text { Elena Gil. }\end{array}$ & & $\begin{array}{lr}\text { Unión } & \text { Femenina } \\
\text { (Valparaíso } & 1950-1951) \\
\text { Unión Femenina de Chile. }\end{array}$ \\
\hline $\begin{array}{l}\text { Amigas. Boletín Unión de } \\
\text { Mujeres de Argentina } \\
\text { (Buenos Aires 1957) } \\
\text { Unión de mujeres de } \\
\text { Argentina. }\end{array}$ & & \\
\hline
\end{tabular}

Entre 1900 y 1920 hubo una gran ebullición de las organizaciones feministas en cada país ${ }^{3}$ que se expresó en la publicación de revistas y periódicos feministas.

13 De esta época es la fundación del Consejo Nacional de Mujeres Argentinas (1900), el Centro Socialista Femenino y la Unión Gremial Femenina, (1902) el grupo Unión y Labor (1909), el Comité Pro Sufragio (1907), la Liga Feminista Nacional (1910) y la realización del Primer Congreso Feminista Internacional (1910) un hito en el feminismo de Argentina. En los 20 se formó el Partido Feminista Nacional (1919), y la Unión Feminista Nacional (1920). En el mismo período en el Uruguay se formó Liga Feminista Nacional (1910), la conocida como la "Universidad de las Mujeres" (1912), el Consejo Nacional de Mujeres (1916), la Alianza Uruguaya de Mujeres para el Sufragio Femenino (1919); sin embargo, el primer partido político, el Partido Democrático Femenino del Uruguay, se fundó en 1935. En Chile, en la década del 10 las feministas fundaron el Círculo de Lectura (1915) en Santiago, y El 
En Chile, hasta los años 20, el feminismo fue de corte liberal, asociado a mujeres de clase media educadas y a algunas mujeres de elite. Su relación con las mujeres obreras fue escasa y sólo se abrió la puerta para la colaboración en la década del 30. Nunca se visibilizó la situación de las mujeres indígenas. El feminismo liberal de las chilenas recogió la tradición del feminismo ilustrado europeo para reclamar igualdad. Un ejemplo fue el discurso de la revista Acción Femenina en su primera época (Santiago, 1922-1923). En ella definieron el "problema femenino" como la ausencia de derechos civiles y políticos. Visibilizaron la acción de las mujeres en el espacio público, defendieron la educación femenina, la participación política y el derecho a voto. Para ello usaron el formato de la revista para mostrar las capacidades de las mujeres aportando a un cambio cultural en el que nuevas figuras femeninas tomaban protagonismo. A la vez complementaron esta labor estableciendo el objetivo de movilizar un gran colectivo de mujeres de Chile en torno al reconocimiento de la desigualdad, haciendo frente al patriarcado: "¿No es una gran pena vernos sometidas a la condición que marcan tales palabras? ¿Hemos de cerrar nuestros oídos a la justiciera voz que nos incita a sublevarnos contra esa triste condición que nos señala? 14

Estas mujeres representaron un cambio cultural que se plasmó en la circulación de publicaciones periódicas que se podían encontrar bajo el brazo de mujeres que usaban el transporte público, en alguna sala de espera y en las mesas de las casas de una creciente clase media. Sin embargo, la cautela fue un rasgo característico de este feminismo. Esto se explica por la autonomía de la acción feminista de las chilenas al disputar un lugar en el espacio público. Se cuidaban de no parecer una amenaza para el orden patriarcal, en un contexto donde el liberalismo chileno había permitido la expresión de múltiples sujetos sociales dentro de un marco legal delimitado, aunque nunca pensó que las mujeres fueran parte de los demandantes. Paralelamente, el feminismo chileno era consciente de que había heredado una historia narrada por varones, y alcanzado conciencia política a través de ideas, acciones y organizaciones propias del poder masculinista. Este fenómeno se expresó en múltiples textos, de los cuales exponemos un ejemplo: "el verdadero feminismo no desnaturaliza a la mujer, por el contrario, la hace mejor doncella, más noble esposa, más experta madre y sobre todo una excelente ciudadana y una poderosa unidad social para el verdadero progreso de la humanidad".15

Consejo Nacional de Mujeres (1919). Los primeros partidos políticos de mujeres chilenos son de la década del 20: Partido Femenino Nacional (1921), Partido Cívico Femenino (1922) y Partido Democrático Femenino (1924). No es el objetivo de este trabajo detallar la acción de las mujeres a través de sus organizaciones.

14 "A lo que aspira el feminismo". Acción Femenina, año 1, no 3, Santiago, noviembre de 1922, pp. 1-2. 15 "¿Qué clase de feminismo defendemos y por qué?, Acción Femenina, año 1, no 1, Santiago, septiembre 1922, pp. 17-18. 
Por su parte, el feminismo argentino mostró cierta unidad entre los distintos grupos, sobre todo entre los de clase media y obreras. El carácter mesocrático de la sociedad argentina contribuyó a la acción conjunta de las diversas organizaciones. A partir de 1919, la actividad feminista se consolidó a través de una diversidad de acciones públicas vinculadas a la lucha por los derechos políticos. En relación con los discursos feministas, se pueden distinguir por lo menos tres vertientes: una asociada al Partido Socialista, representado por Alicia Moreau; otra feminista radical, asociada a Julieta Lanteri; y una moderada, liderada por Elvira Rawson, del Partido Radical.

La revista Nuestra Causa es un buen ejemplo para mostrar la convergencia de los grupos feministas argentinos en su lucha por los derechos políticos y civiles de las mujeres. A pesar de que la revista es el órgano de difusión de la Unión Feminista Nacional, organización creada en 1918 por las mujeres socialistas, la publicación recogió las otras posturas del feminismo porteño. Se caracterizó por alejarse de la justificación maternalista en la demanda por la igualdad de derechos y se acercaron a posturas de la razón ilustrada. Su planteamiento fue fuerte, acorde con el momento de alza del feminismo argentino, en el contexto de los gobiernos radicales. El número 1 de Nuestra causa, de mayo de 1919, muestra la consolidación de las organizaciones a cargo de nuevas mujeres:

El movimiento feminista no es ya una manifestación aislada de unas cuantas exaltadas, excéntricas, que inspiraban repulsión, es ahora una evolución mundial, que nada ni nadie podrá reprimir. Es necesario estudiar esas manifestaciones y sobre todo las mujeres deben conocer lo que pretenden las feministas 16 .

La discusión académica ha establecido que el feminismo uruguayo se desarrolló a partir de la década del 20 (Lavrín, 1995). Sin embargo, se debe considerar la acción de las feministas anarquistas como antecedente del movimiento por la emancipación de las mujeres uruguayas. Obreras y sufragistas se entroncaron en la demanda por mejores condiciones de vida para trabajadoras, por un lado, y ciudadanas, por otro, y en ningún caso se incluyó la condición de las mujeres negras. Desarrollaron fórmulas distintas: la demanda del voto como piedra angular de todos los derechos para unas, y el reclamo de igual salario por igual trabajo, para las otras (Sapriza, 2015). Uno de los factores impulsores del feminismo del Uruguay fue el proyecto político de José Batlle y Ordoñez, presidente entre 1903 y 1907, y luego entre 1911 y 1915. En él se favorecía a los sectores urbanos (clase media, proletariado industrial, inmigrantes incluidos) en la extensión de la ciudadanía como base de un "Estado de Bienestar". Para las mujeres esto significó un apoyo directo

16 Petronila Eyle. "Nuestro anhelo". Nuestra Causa, no1, Buenos Aires, mayo 1919, p 2. En Edit Galloh. Nuestra Causa... p. 29. 
del presidente al voto femenino y a la educación de las mujeres a través de la "Universidad de Mujeres", aunque no necesariamente se tradujo en leyes concretas. En realidad se creó un mito en relación con la igualdad entre varones y mujeres en el Uruguay.

A partir de la década del 10, las feministas uruguayas se concentraron en conseguir sus derechos y formaron el Consejo Nacional de Mujeres (1916). Con la dirección de Paulina Luisi, iniciaron una arremetida a través de la revista Acción Femenina (Montevideo, 1915-1925). El Consejo estaba compuesto por mujeres de la elite y clase media educada, cercano al feminismo liberal, y aunque no desconocía a las obreras, existía una total invisibilidad de negras y campesinas. Su horizonte era conseguir los derechos políticos a través de la vía legal, asociando la lucha por la paz, la educación de la mujer, el libre acceso a profesiones e igual remuneración por igual rendimiento. También se plantearon contra la trata de blancas y prostitución reglamentada, la doble moral sexual y la defensa de las madres solteras (Rodríguez, 2004).

La revista Acción Femenina fue tanto la expresión de unas nuevas figuras femeninas como el medio de difusión de las mismas. La materialización de la revista fortaleció el discurso feminista enfrentándose a la autoridad, como se ve en la siguiente cita:

y nos preguntamos qué salvaje ironía o qué obtusa inconciencia inspiraban las palabras de aquellos constituyentes que no tuvieron reparo en negar a la mujer el derecho a la vida ciudadana en nombre de lo más sagrado de todos los deberes: pero que, a estas esclavas del hambre, siquiera en nombre de la maternidad humillada, no saben proteger como legisladores, ni muchas veces saben respetar como hombres! Por eso, repetimos, la mujer debe ser redimida. Por eso llamamos al corazón de todas las mujeres, para que nos acompañen en esta obra de liberación de nuestro sexo; y que, en la medida de sus fuerzas, en el desarrollo de sus aptitudes en la labor que su bondad y su inteligencia les inspiren, hagan causa común con nosotras, en esta cruzada de justicia, en esta obra de redención que será tarea de este siglo17.

En la década del 30, los países del Cono Sur viven los embates de una crisis mundial que tuvo manifestaciones económicas y políticas. Como países exportadores de materias primas, vieron deterioradas las condiciones de vida de sus habitantes, lo que fue especialmente trágico en Chile. Sumado a ello, el avance del fascismo

17 La Dirección "Nuestro programa”. Acción Femenina. Revista Mensual. Consejo Nacional de Mujeres del Uruguay. Año 1, no 1, julio 1917 (pp. 1-4). 
significó una radicalización de los discursos de izquierda. Los feminismos de estos países no fueron ajenos a ello y tomaron fuerza al defender no sólo los derechos femeninos, sino al entroncarse con luchas transnacionales como la defensa de la paz y el antifascismo. Todo ello se tradujo en una prensa política de mujeres radicalizada en los tres países.

En Chile, la radicalización fue muy evidente y uno de los ejemplos más significativos fue la revista La Mujer Nueva (Santiago, 1935-1941), publicada por el Movimiento Pro Emancipación de la Mujer Chilena, Memch. Esta fue una organización única en su tipo, ya que se declaró feminista radical, defendiendo su autonomía por sobre todas las cosas. A pesar de ello, estableció alianzas con las otras organizaciones feministas como el Partido Cívico Femenino, que también radicalizó su discurso. El giro a la izquierda del feminismo chileno en los años 30 lo llevó a establecer alianzas con partidos políticos en la lucha contra el fascismo, como el Partido Comunista y el Socialista. Esto no significó que renunciara a la mirada de género de los problemas políticos y sociales. La radicalización del discurso se observa en el uso del formato: un periódico que implica una urgencia y que apela a la acción de las lectoras. También se usaron imágenes desgarradoras y un lenguaje que hablaba directamente. Este fenómeno evidencia la transformación cultural sobre las posibilidades de acción de las mujeres. Éstas son figuras femeninas que no piden permiso para opinar o llamar la atención de algo. Exigen un cambio desde un lugar seguro y que les permite extender una red feminista nacional e internacional. De hecho, hubo un intenso intercambio entre La Mujer Nueva de Chile y Vida Femenina de Argentina.

La radicalidad de La Mujer Nueva se expresó en la discusión de los diversos problemas sociales que golpeaban especialmente a las mujeres. Se discutió la relación mujer-trabajo-maternidad, traducida en múltiples problemáticas para las que no existía legislación: derechos maternales para las trabajadoras, educación sexual para la anticoncepción y el aborto, derecho a asignación familiar y condiciones de trabajo dignas. En relación con la sexualidad, denunciaron la doble moral para hombres y mujeres que repercutía en la propagación de enfermedades venéreas. En relación con la situación de las mujeres en la sociedad, hicieron una mirada crítica de la maternidad, la protección de la infancia y de la familia, y defendieron el divorcio. Por primera vez en Chile un grupo de mujeres ponía en cuestión el rol tradicional de ser madres. La que sigue es sólo una muestra de cómo se utilizó el dramatismo en función de la movilización feminista:

Malestar, la cabeza oprimida por un anillo de hierro, angustia física, angustia que estruja el estómago, náuseas, sudor frío. Pero es menester levantarse para llegar a tiempo al trabajo: es necesario vencerse porque al fin de la semana el salario significa su pan y el pan 
de sus hijos. (...) ¡Detenerse! ¡Descansar! ¡Pero no es posible! (...) Es menester seguir. Seguir, mientras sus miembros doloridos obedezcan los mandatos de la voluntad. Y así un día tras otro hasta que su cuerpo se desdoble en la mueca feroz del parto. Ya tiene pegado a su pecho un pequeño ser insaciable, ¡Es su hijo! ¡Un nuevo hijo! Pero en lugar del sentimiento de ternura y de orgullo que ordenan los cánones, sólo una preocupación la embarga. ¡Una boca más!18.

La década de 1930 se inició en Argentina con el golpe de Estado del General Uriburu, y el conservadurismo que significó su gobierno hizo que la actividad feminista encontrara nuevas formas de actuar. Una de ellas fue compartir el activismo con organizaciones no necesariamente feministas o de mujeres, como las pacifistas. El feminismo mantuvo su estabilidad en las organizaciones feministas socialistas, aunque debido al contexto, acomodó sus objetivos. Esto quitó fuerza a la defensa de derechos políticos y privilegió la defensa de la democracia y la libertad (Barrancos, 2007: 175-176). La defensa de la República española fue un aliciente que imprimió fuerza al discurso feminista argentino representado por las socialistas, y que se expresó particularmente en Vida Femenina (Buenos Aires, 1933-1941).

Vida Femenina fue una publicación estable que salió mensualmente sin interrupciones por 11 años. En ella se trataban problemas de las mujeres, aunque había un acento importante en la denuncia al avance mundial de los totalitarismos y de la corrupción de la política local. La publicación representó un llamado dramático de las socialistas en defensa de la participación femenina ante las limitaciones que el discurso nacionalista asignó a las mujeres en la década del treinta (Masiello, 1997: 228). Ante la agudización de los problemas sociales que pintaron un cuadro de descomposición social, llamaron a intervenir con un discurso movilizador como el que expresa Alicia Moreau en el siguiente texto:

Pero hoy! Tenemos la sensación del caos. La guerra interrumpiendo brutalmente la lenta obra constructiva, lanzando al obrero, al artista, al maestro, al campesino confundidos atrozmente en el campo de matanza, nos ha hecho perder todos nuestra confianza en el porvenir. (...) Todo está dominado por el deseo de violencia, de velocidad, de audacia, de fuerza. (...) Son la expresión de una humanidad cuya sensibilidad exhausta exige, para reaccionar, excitantes cada vez más fuertes. Solo esto nos explica la indiferencia ante la amenaza de una nueva guerra. (...) No, la solución no vendrá remontando la corriente de la historia, volviéndonos hacia instituciones o prácticas medioevales sino ampliando y perfeccionando la democracia. Y he ahí donde la

\footnotetext{
18 Junious. “Maternidad”, La Mujer Nueva, no3, enero 1936, Santiago de Chile, p. 1.
} 
mujer representa una de las fuerzas nuevas que han de servir el momento presente. De esta nueva fuerza femenina, que no ha tomado aún conciencia de sí misma, que sigue por el momento los derroteros marcados por el hombre, debemos esperar un aporte salvador que para llegar exija tal vez la experiencia de más de una generación ${ }^{19}$.

En Uruguay, la crisis económica llevó a un cuestionamiento del reformismo social del batllismo. El mito de país moderno e igualitario se resquebrajó mostrando una realidad de desigualdad en el peor momento de crítica a la democracia occidental. 1933 se inició con un golpe de Estado que reprimió a los movimientos sociales, aunque contó con el apoyo de militares y partidos políticos que terminaron por legitimarlo en elecciones durante el mismo año. En este panorama, el feminismo uruguayo se concentró en el sufragismo, uniendo a feministas radicales y moderadas. El activismo se tradujo en la presentación de diversos proyectos para lograr su objetivo que consiguió en 1932, una década antes que en Argentina y Chile. Sin embargo, este logro no significó necesariamente una mayor representación formal de las mujeres, ni una mejora en las condiciones de vida, aunque se cerró una etapa (Sapriza, 2015). A partir de allí se organizaron esfuerzos por mantener a las mujeres activas en la política uruguaya con representación propia y, por ejemplo, se formó el Partido Democrático Femenino del Uruguay (1933). Este partido tuvo su propio órgano de difusión a través del periódico Ideas y Acción (Montevideo, 1933), donde llamaba a continuar la lucha por la igualdad de las mujeres:

[Esta] nueva entidad política independiente de los demás partidos, desarrollará el postulado social de equiparación de los sexos corrigiendo todas las desigualdades e injusticias que aún perduran en nuestra organización social como fruto de las doctrinas y prejuicios que otorga al hombre una situación preponderante de privilegios y formulará paralelamente un vasto y justiciero programa de Acción Social tendiente a realizar el mayor beneficio del país y la colectividad entera. 20

La postura de continuar una lucha feminista chocó con otras que la consideraban falta de sentido, dado el nuevo panorama. Así se expresaba en América Nueva (Montevideo, 1932-1933), publicación que se decía defensora del sufragio femenino, pero que cuestionaba la existencia de organizaciones autónomas de mujeres, ya que consideraba que los partidos tradicionales recogían las demandas femeninas. De hecho, afirmaba que las mujeres habían sido sorprendidas con el

19 Alicia Moreau, “¿Cuál será el Porvenir de nuestros hijos?”, Vida femenina Año I, número 4, Buenos Aires, noviembre 1933.

20 Manifiesto al país. Ideas y Acción, Montevideo, nำ1, p. 1. 
derecho a voto porque "está demostrando que no sabe aún qué camino tomar (...) En todo caso, se coloca en la situación menos apetecible, la que dejaría las posiciones tal como estuvieron hasta hoy: frente a frente, el hombre y la mujer en una absurda lucha de $\operatorname{sexos}^{\prime \prime} 2$.

Falta investigación específica para explicar esta confrontación en el feminismo uruguayo de los 30. Sin embargo, puede relacionarse con el silencio feminista que se ha establecido para otros países latinoamericanos luego del reconocimiento del voto femenino. En lo concreto, la prensa feminista que se desarrolló en el Uruguay después de esta coyuntura disminuye considerablemente. Una muestra de ello es la publicación de carácter magazinesco, La Mujer (Montevideo, 1938), que desarrolla algunas cuestiones generales sobre la condición de las mujeres, pero mezcladas con misceláneos y notas de la realidad nacional e internacional.

En la década del 40, la prensa feminista de los países del Cono Sur sufre una disminución considerable. En general se puede hablar de una institucionalización (Montero, 2013: 349). Esto se expresa en que las publicaciones cambian su formato y pasan a ser mayoritariamente boletines. Este cambio dice mucho, ya que las publicaciones pierden su carácter de difusión de los objetivos de las organizaciones hacia el espacio público y comienzan a ser informativos internos. Esta realidad se ve más claramente en Chile y Uruguay, ya que Argentina muestra una producción que continúa dando cuenta de organizaciones activas, estables y sobreponiéndose al silencio feminista (Kirkwood, 1990) post consecución de derechos políticos.

El decaimiento en la producción de prensa de mujeres en Chile se vive a pesar de que en los 40 el feminismo cobró fuerza en la lucha por el voto. Se organizó reuniéndose en la Federación Chilena de Instituciones Femeninas, FECHIF (1944), que publicó su boletín entre 1944 y 1947. En 1949 las chilenas fueron reconocidas como ciudadanas con plenos derechos. Esta calidad las habilitaba para acceder a cargos de elección popular, sin embargo, las dos candidatas que ganaron elecciones (María Inés de la Cruz como senadora en 1953 e Inés Enríquez como diputada en 1958) fueron destituidas, en un claro intento por detener a las mujeres en el ámbito político (Gaviola, 2007). En Uruguay, con ya varios años de reconocimiento de las mujeres como ciudadanas, la década del 40 vio a las primeras mujeres en cargos de elección popular. Muchas de ellas eran militantes del Partido Colorado que participaron del Comité Nacional Batllista (1942). Con su acción en el parlamento consiguieron la reforma del Código Civil, un gran deseo feminista, aunque logrado por mujeres adscritas a un partido político tradicional. Como ejemplo de la institucionalización de la prensa de mujeres de este período en el Uruguay está el

21 Zulma Núñez. "La mujer y sus derechos”. América Nueva. Revista Quincenal Uruguaya. Montevideo. Enero 15 de 1933, no 8. 
periódico Mujer Batllista/Comité de Organización femenina Batllista Doña Matilde Pacheco de Batlle y Ordóñez (Montevideo, 1946).

En Argentina, la década del 40 está marcada por el ascenso del peronismo. En relación con las luchas de las mujeres, el peronismo a través de la figura de Evita cooptó la demanda por el sufragio femenino. Lejos de poder ser considerada feminista, levantó el voto femenino como una bandera propia, al ser sancionado en 1947. Sin embargo, hubo oposición al peronismo por parte del activismo femenino. Parte de ello se expresó en la continuidad de la acción de las feministas socialistas, como por ejemplo a través de la revista Ciudadanas Unión de mujeres socialistas (Buenos Aires, 1956). Allí continuaron su labor reconocidas feministas como Alicia Moreau y María L. Berrondo. Otra organización, aunque no necesariamente feminista, fue la Unión de Mujeres Argentinas (1947), brazo del Partido Comunista, que publicó Nuestras Mujeres (Buenos Aires, 1948-1963), la cual mostró un giro hacia la defensa de los derechos de las mujeres, justificado en el maternalismo (Barrancos, 2007). Si se cuentan las publicaciones políticas de y para mujeres que asumen la defensa de los derechos de las mujeres en Argentina entre 1940 y 1950, se puede ver una aparente actividad que cuestiona el silencio feminista que se dio en Uruguay y Chile. Sin embargo, la naturaleza de las organizaciones, muchas de ellas no necesariamente críticas al sistema de exclusión femenina y más cercanas a un asistencialismo (Barrancos, 2007), permite acercarse a la idea de una dilución del feminismo expresado en la prensa.

\section{Conclusión}

El panorama de la prensa política de y para mujeres entre 1900 y 1950 en los países del Cono Sur es tan amplio y rico que el espacio de este artículo no alcanza para profundizar en sus detalles. Sin embargo, a partir de la pequeña muestra que hemos desarrollado, se pueden sacar algunas conclusiones referidas a cómo las mujeres feministas (entendidas en el amplio concepto de defensa de la condición de las mujeres en la sociedad), tomaron la prensa como un objeto para aprovechar las posibilidades que entrega el medio para conseguir objetivos políticos. A la vez, las publicaciones pusieron en circulación figuras femeninas que cambiaron prácticas culturales desafiando los roles tradicionales de las mujeres. La prensa política de mujeres fue a la vez la expresión de nuevas mujeres, como el medio por el que ellas se expresaron.

Estas publicaciones representaron un gran impacto en la cultura de los países del Cono Sur, ya que ampliaron las posibilidades de ser de las mujeres, haciendo evidente una acción femenina como sujeto social capaz de cambiar sus condiciones de vida. La reacción a tal cambio fue la circulación de caricaturas de feministas representadas como feas, histéricas o solteronas. 
Si bien el feminismo del Cono Sur no representó dobles o triples exclusiones de mujeres indígenas, negras o campesinas, fue heterogéneo en la medida que dio cuenta de las diferencias de clase e ideológicas de mujeres de elite, obreras, socialistas, anarquistas y liberales.

El gran impacto de estas publicaciones fue el de materializar el feminismo en un objeto cultural, frente al cual no se podía negar su existencia. Por ejemplo, podemos ver cómo la prensa, tanto de obreras como feminista, fue la expresión de colectivos de mujeres que eran conscientes de una nueva realidad y del papel que jugaban en la sociedad. Ambos tipos analizados en este trabajo muestran un feminismo entendido como contradiscurso, ya que expresó subjetividades que cuestionaron el rol asignado por el patriarcado. Las obreras, ya sea anarquistas o socialistas, visibilizando a las mujeres como trabajadoras y víctimas del sistema capitalistas; o las feministas que evidenciaron la exclusión como sujetos de derechos. En ambos casos, muestran otra interpretación de ellas mismas a través de publicaciones que desafiaron los patrones de género que clasificaban a las mujeres como lectoras y productoras de textos livianos, magazinescos, carentes de opinión.

El orden social jerarquizado por patrones de genero también se expresó en la dificultad que tuvieron las mujeres para mantener con vida muchos de sus medios. No hubo espacio para ver la relación con el tiempo de la prensa política de mujeres, pero una mirada rápida de las tablas muestra la corta vida de muchas de las publicaciones. La jerarquización de género también se puede observar en el auge y caída que representa de la prensa política de mujeres del Cono Sur en la primera mitad del siglo XX: concentrada a inicios de siglo en la de obreras socialistas y anarquistas, gracias a la explosión del movimiento obrero de los respectivos países, aunque no exenta de críticas por parte de sus compañeros; gran presencia de feministas en los años 20, influida por un movimiento internacional de demanda de derechos políticos para las mujeres; su transformación en los años 30 producto de la crisis; y su dilución a partir de los años 40 , producto de la institucionalización y cooptación de las mujeres por partidos políticos una vez alcanzado el voto.

Sin embargo, es importante rescatar que las mujeres del Cono Sur supieron aprovechar las posibilidades que ofrecía el formato de la prensa para lograr sus objetivos políticos. La prensa posee en sí misma una rapidez de respuestas ante las contingencias que permitió la transformación del discurso feminista, considerando los distintos contextos políticos, sin hipotecar su crítica al sistema patriarcal. Supo acomodarse a las circunstancias regulando la radicalidad de las posturas, asociándose con otras demandas de movimientos sociales afines para sostener su crítica final: la subordinación de las mujeres por el patriarcado. 


\section{Bibliografía}

Arango-Keeth, F. (2002): "Del "ángel del hogar" a la "obrera del pensamiento": construcción de la identidad sociohistórica y literaria de la escritora peruana del siglo XIX”, en J. A. García y S. B. Guardia, eds., Historia de la mujer en América Latina. Murcia, Universidad de Murcia.

Barrancos, D. (1989): Anarquismo, educación y costumbres en la Argentina de principios de siglo. Buenos Aires, Contrapunto.

Barrancos, D. (2007): Mujeres en la sociedad argentina. Una historia de cinco siglos. Buenos Aires, Sudamericana.

Bellucci, M. (1994): "De la pluma a la imprenta", en L. Fletcher, comp., Mujeres y cultura en la Argentina del siglo XIX. Buenos Aires, Feminaria, pp. 252-263.

Berman, M. (1994): "Brindis por la modernidad", en N. Casullo, comp., El debate Modernidad/Posmodernidad. Buenos Aires, El Cielo por asalto, pp. 67-91.

Chartier, R. (1992): El mundo como representación. Estudios sobre historia cultural. Barcelona, Gedisa.

De Miguel, A. (1995): “Feminismos", en C. Amorós, Diez palabras clave sobre mujer. Pamplona, Verbo Divino.

Feijóo, M. C. y M. Nari (1994): "Imaginando las/los lectores de La Voz de la Mujer", en L. Fletcher, comp., Mujeres y cultura en la Argentina del siglo XIX. Buenos Aires, Feminaria, pp. 276-284.

Fraser, N. (1992): "Repensando la esfera pública: una contribución a la crítica de la democracia actualmente existente", en C. Calhoun, ed., Habermas and the Public Sphere. Cambridge, MIT Press, pp. 109-142.

Fuentes, G. (2008): Protagonistas y Olvidadas. De la mujer de la Independiencia a la Independencia de la Mujer. Montevideo, Orbe.

Gaviola, E., X. Jiles, L. Lopestri y C. Rojas (2007): Queremos votar en las próximas elcciones. Histroia del movimiento femenino chileno 1913 - 1952. Santiago, Lom. 
Halperin Donghi, T. (1985): "Economy and Society in post-Independence Spanish America", en L. Bethell, ed., The Cambridge History of Latin America, Vol III. Cambirdge: Cambridge University Press.

Hobsbawn, E. (1998): La Era del capital, 1848-1875. Buenos Aires, Crítica.

Hutchison, E. (2006): Labores propias de su sexo. Género, políticas y trabajo en Chile urbano 1900-1930. Santiago, Lom.

Illanes, M. A. (2012): Nuestra historia violeta. Feminismo social y vidas de mujeres en el siglo XX: una revolución permanente. Santiago, Lom.

Kirkwood, J. (1990): Ser Política en Chile. Santiago, Cuarto Propio.

Lavrín, A. (1995): Women, Feminism, and Social Change in Argentina, Chile, and Uruguay, 1890 - 1940. Lincoln y Londres, University of Nebraska Press.

Lobato, M. (2009): La prensa obrera. Buenos Aires y Montevideo 1890-1958. Buenos Aires, Edhasa.

Masiello, F. (1994): La Mujer y el Espacio Público. El periodismo femenino en la Argentina del siglo XIX. Buenos Aires, Feminaria.

Masiello, F. (1997): Entre civilización y barbarie. Mujeres, Nación y Cultura Literaria en la Argentina moderna. Rosario, Beatriz Viterbo Editora.

Molyneux, M. (2003): Movimientos de mujeres en América Latina. Estudio teórico comparado. Madrid, Cátedra.

Montero, C. (2013): "Cincuenta años de Historia de la prensa de mujeres en Chile", en J. Fermandois y A. M. Stuven, eds., Historia de las mujeres en Chile. Tomo II. Santiago, Taurus, pp. 319-354.

Montero, C. (2016): “Trocando agujas por la pluma: las pioneras de la prensa de y para mujeres en Chile 1850-1890", Meridional. Revista Chilena de Estudios Latinoamericanos, (7), pp. 55-81.

Nash, M. (2004): Mujeres en el mundo. Historia, retos y movimientos. Madrid, Alianza. 
Osuna, R. (1998): Tiempo, materia y texto. Una reflexión sobre la revista literaria. Kassel, Reichenberger.

Poblete, J. (2003): Literatura Chilena del siglo XIX: entre públicos, lectores y figuras autoriales. Santiago, Cuarto Propio.

Pratt, M. L. (1995): "Don't interrupt me. The gender essay as conversation and countercanon", en Doris Meyer, ed., Reinterpreting the Spanish American Essay. Women writers of the 19th and 20th century. Austin, University of Texas Press.

Rodriguez, S. (2004): "Los papeles de la mujer en una sociedad de cambio. 19161932”, en G. Peluffo, coord., Los Veinte: El proyecto uruguayo. Arte y Diseño de un imaginario, 1916-1934. Montevideo, Roemers, pp. 113-120.

Sapriza, G. (2015): "Experiencias y Perspectivas de Participación Política de las Mujeres en América Latina y Caribe Argentina, Chile, Uruguay”. s/d.

Scott, J. (1996): "El Género: una categoría útil para el análisis histórico", en M. Lamas, comp., El Género: la construcción cultural de la diferencia sexual. México D.F., UNAM, pp. 265-302.

Subercaseaux, B. (1989): Fin de Siglo, La Epoca de Balmaceda. Santiago, Aconcagua.

Valdés, T. (2000): De lo social a lo político. La acción de las mujeres latinoamericanas. Santiago, LOM.

Fecha de recepción: 18 de abril de 2020

Fecha de aceptación: 9 de junio de 2020 